\title{
A Study of Management of Subtrochanteric Fractures Treated by Proximal Femoral Nail - A Prospective Study
}

\author{
Venkateswara Rao Dasari ${ }^{1}$, Shyam Kumar Chinta², Mounika CNS ${ }^{3}$, Prathyusha Azari ${ }^{4}$ \\ 1, 2, 3, 4 Department of Orthopaedics, Siddhartha Medical College, Vijayawada, Andhra Pradesh, India.
}

\section{ABSTRACT}

\section{BACKGROUND}

The proximal femur nail (PFN) is one of many intramedullary nails that have been designed for the early mobilisation and secure fixation of subtrochanteric fractures.

\section{METHODS}

We conducted a prospective study at our institute between November 2018 and November 2020 on a hundred patients who had high subtrochanteric fractures and were treated with proximal femoral nailing. Ninety-five patients had fracture fragments reduced to within a few millimetres of their anatomical size, whereas five needed limited open reduction.

\section{RESULTS}

In the current study, nine $(7.76 \%)$ of the cases had superficial infections; no deep infections were observed. In five cases (5.76\%), we found an anti-rotational screw cut-off. Three ( 4.75 percent) of the patients had shaft fractures with nail breaking. In the present series, the mean modified Harris Hip Score was 81.24, ranging from 100 to 29. Regardless of fracture kind, all of the patients between the ages of 20 and 30 achieved good results (80.77 percent) in this study. Patients in the older age group had comparatively bad results (19.33\%), with 50 percent (5) having poor results and five (50\%) having good to fair results.

\section{CONCLUSIONS}

Patients in the older age groups did not have a good outcome in this series. These findings suggest that to reduce problems, a meticulous surgical technique and adjustments tailored to the individual fracture pattern are required. The advantages of the high rotational stability and unreamed insertion method of the head-neck fragment, as well as the potential of static or dynamic distal locking, are emphasized in osteosynthesis of the proximal femoral nail.

\section{KEY WORDS}

Proximal Femur Nail, Subtrochanteric Fractures
Corresponding Author: Dr. Prathyusha Azari, Postgraduate,

Room No. 403, New Women's Hostel, Siddhartha Medical College, Gunadala, Vijayawada-520008, Andhra Pradesh, India.

E-mail: prathyumercy@gmail.com

DOI: $10.14260 /$ jemds $/ 2022 / 36$

How to Cite This Article:

Dasari VR, Chinta SK, Mounika CNS, et al. A study of management of subtrochanteric fractures treated by proximal femoral nail - a prospective study. J Evolution Med Dent Sci 2022;11(01):189-193, DOI: $10.14260 / \mathrm{jemds} / 2022 / 36$

Submission 23-02-2021,

Peer Review 17-01-2022,

Acceptance 25-01-2022,

Published 29-01-2022.

Copyright (C) 2022 Venkateswara Rao Dasari et al. This is an open access article distributed under Creative Commons Attribution License [Attribution 4.0 International (CC BY 4.0)] 


\section{BACKGROUND}

Urbanization and civilization have brought both challenges and benefits to people all around the world. ${ }^{1}$ Fast-paced lifestyles, high-speed transportation, hazardous infrastructure projects, and the most advanced commando warfare actions have all increased morbidity and death, notably femur fractures, as a result of trauma.

Upper femoral fractures requiring efficient neutralization of deforming stresses offered a unique problem ${ }^{1}$ among femoral shaft injuries.

Due to a particular muscle insertion to the proximal and distal fragments, very significant mechanical stresses develop at the junction of the trabecular and cortical zone ${ }^{2}$ and the deforming forces.

Due to these features, subtrochanteric fractures require specific attention in orthopaedic trauma because a poor union of these fractures results in a higher level of handicap for the individual, as a result, the most worthful days of human life have been lost. As a result, the orthopaedic community is continually on the search for the most effective and appropriate approach to treat upper femur fractures.

For a variety of designs and procedures, the surgical management of fractures and other surgical implants has altered. Various centres use a variety of upper femoral devices, such as the dynamic condylar screw, ${ }^{3}$ dynamic hip screw with barrel plate, ${ }^{4}$ gamma nail, ${ }^{5}$ proximal femoral nail, ${ }^{6}$ each centre claims that each equipment gives adequate results, and so on.

A $135^{\circ}$ dynamic hip screw was used with a valgus reduction to treat unstable peri trochanteric fractures. Because of its great results and little risk of non-union or hardware failure, the dynamic hip screw is the implant of choice despite this, literature has revealed substantial cut-out rates (5-17\%). Therefore, dynamic hip screw and sliding plate remain the most used surgical implant for these types of fractures. The purpose of this study was to evaluate the usability and effectiveness of the proximal femur nail, which was developed by A0-ASIF7 in 1997, for various forms of upper femoral fractures over a year. One hundred and eightynine proximal femoral fractures were treated with a proximal femoral nail. After at least four months of follow-up, 4.6 percent of the cases had technical issues such as inadequate reduction, malrotation, or the incorrect choice of implants (screws). In one example.

There were no mechanical failures at the implant's tip, such as bending, implant breakage, or ipsilateral femoral shaft fractures, while in another case, there were no mechanical failures such as bending, implant breakage, or ipsilateral femur shaft fractures at the implant's tip. As a result, these new implants for treating unstable per trochanteric femoral fractures are considered to be superior to those of currently available implants. 6,8

\section{Objectives}

A.O. proximal femoral nailing, the outcome of surgically managed subtrochanteric fractures was studied using this design type.

\section{METHODS}

The case series includes patients who were admitted to the Government General Hospital in Vijayawada's Orthopaedic Department between November 2018 and November 2020.

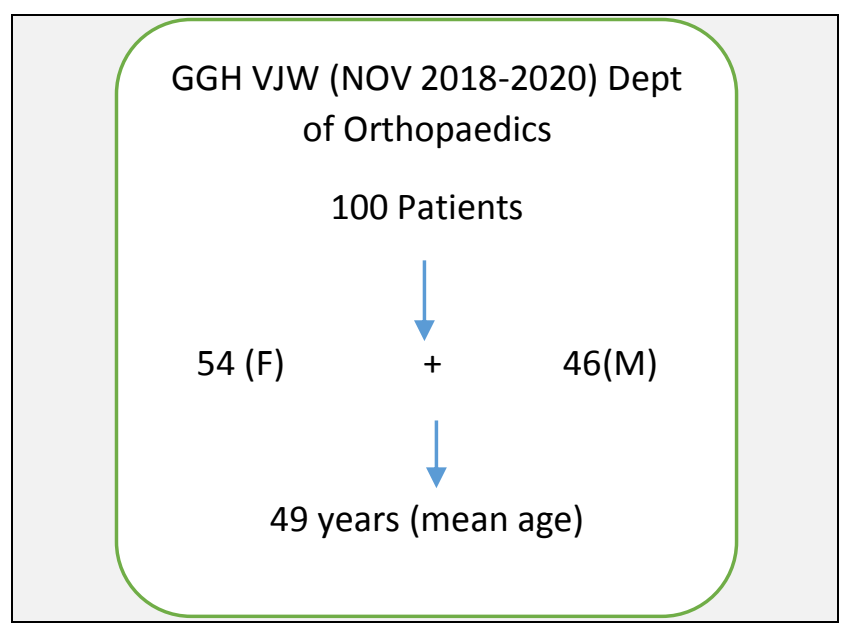

Pathological fractures, as well as subtrochanteric fractures with ipsilateral femur shaft or neck fractures, are not included in this case series.

Clinical and hemodynamic evaluations began as soon as the patients arrived. Patients were admitted to orthopaedic wards and kept on skin traction till surgery based on immediate pelvic radiographs, anteroposterior view, fulllength thigh A.P, and lateral views. Appropriate investigations were conducted, surgical fitness was determined, and the patient was operated in a supine position on the fracture table under image intensifier control using standard techniques. They were discharged on the tenth postoperative day after the sutures were removed, and their recovery was uneventful. Depending on the fracture, they were evaluated clinically and radiologically on the second postoperative day, as well as after six weeks, three months, and between six months and one year. In this study, the functional outcomes were measured using the modified Harris Hip Score. ${ }^{9}$

\section{RESULTS}

Between November 2018 and November 2020, a total of 100 Subtrochanteric femur fractures were admitted and operated at GGH, Vijayawada, Department of Orthopaedics, accounting for around 24.8 percent of all femur fractures.

Age group in the present series is twenty-three years old to seventy-five years. With an average age of 49 years, the older age group has the most patients. In this study, women had a slightly higher rate of subtrochanteric fractures than men. Twenty-eight (60.8 percent) boys in the current series suffered this injury as a result of high-velocity trauma. Women are more prone than men to be injured by lowvelocity trauma. A total of 34 females $(63 \%)$ were injured as a result of low-velocity trauma. Males are 36 years old on average, while females are 64.27 years old. As a result, female patients were older than male patients and hence more susceptible to low-velocity trauma. Women are more likely to have subtrochanteric fractures than men. 

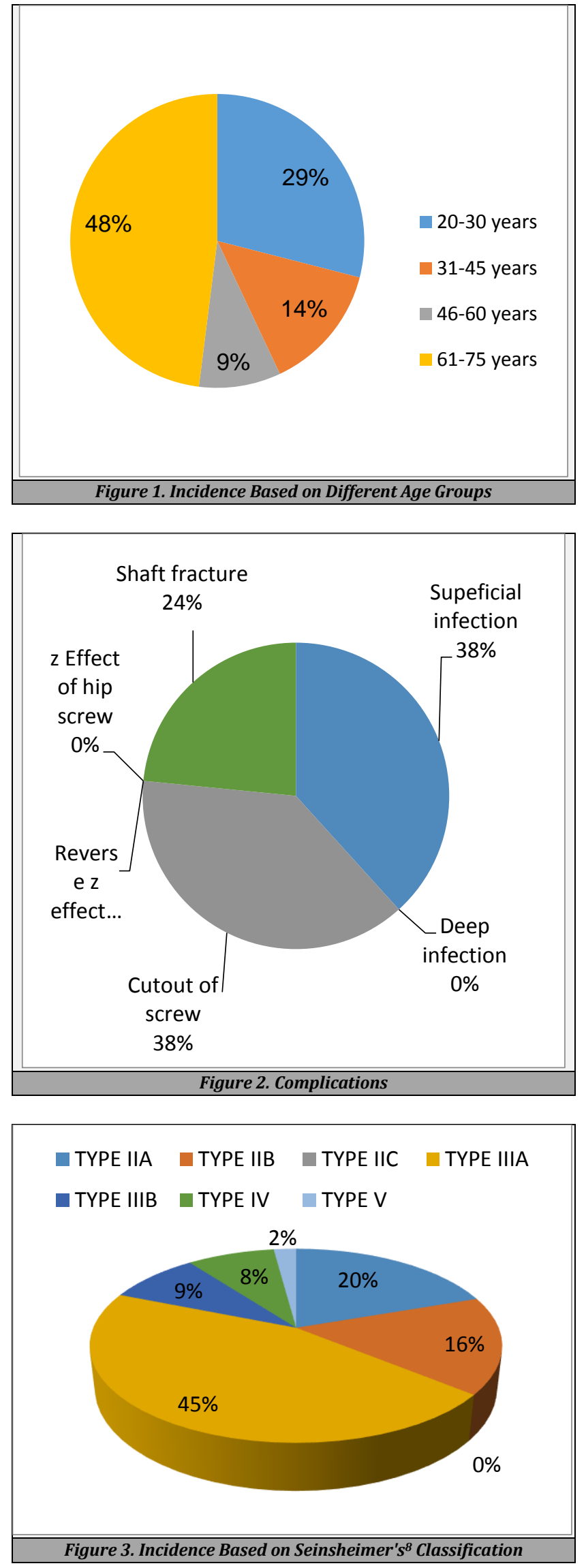

In the current series, the operation injury-time interval is 6.6 days. This longer period is primarily due to the patient's uncontrolled pre-existing illness at the time of presentation. The most common fracture pattern in the current series is Seinsheimer's ${ }^{8}$ type III-A.
In the current series, seven $(7.76 \%)$ of cases had surface infections, while no deep infections (0) were found. In five cases (5.76 percent), an anti-rotational screw cut-off was seen. In three cases (4.75\%), the femur shaft fractured with the nail breaking off. 72 percent of the participants in this study reported little or minor discomfort that interfered with their regular activities. Only five of the cases were in severe pain. In $23 \%$ of the patients, analgesics were administered to relieve minor discomfort. In the current study, 79 percent of the participants had no or a minor limp that interfered with their regular activities.

However, twelve percent (12\%) of the participants showed a mild to moderate limp, owing to shortening. In the current study, 86 percent of patients did not require any assistance in walking, whereas seven percent $(7 \%)$ required the use of a cane for long journeys. Only three of the patients were able to walk without crutches. The usage of a cane is essential due to the patients' advanced age and concomitant osteoarthritis. In the current study, seventy-eight patients $(78 \%)$ were able to climb the stairs without assistance, whereas eleven patients $(11 \%)$ required handrail assistance. One patient was unable to mount the stairwell, which is a typical occurrence. Squatting was achievable in 87 percent of the members, with ease in 77 cases and difficulty in 11 cases (11 percent). Two of the patients were unable to squat. Squatting remains difficult in elderly persons with osteoarthritis. Two of the instances had shortness of more than two centimetres, necessitating a shoe increase. One patient had a two-centimetres shortening and did not require treatment. The mean modified Harris Hip Score ${ }^{9}$ in the current series is 81.24 , with scores ranging from 100 to 29 .

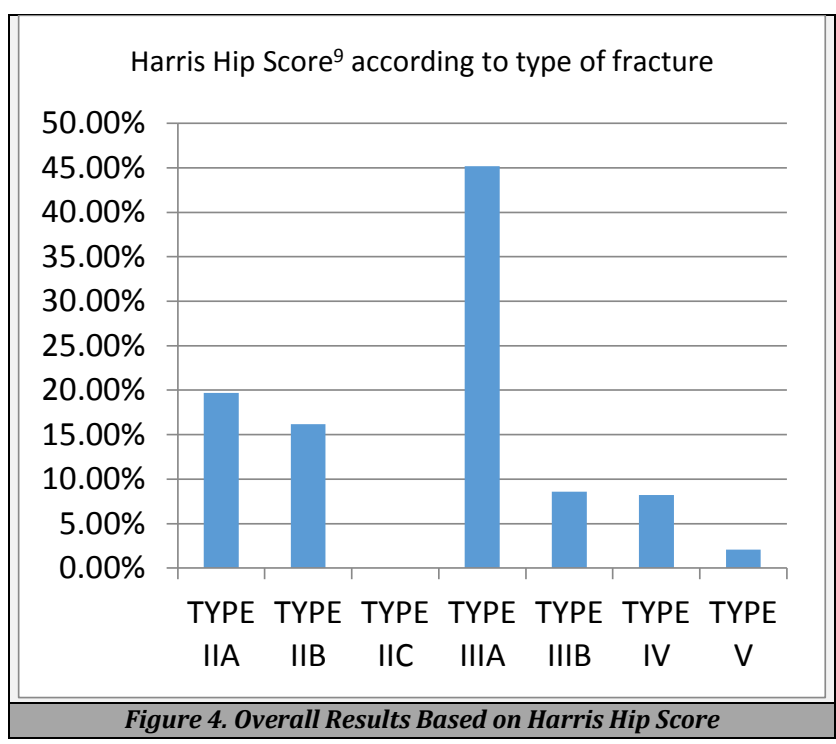

Regardless of the fracture type, all of the patients in this series between the ages of 20 and 30 had outstanding results, Patients in the older age groups had worse outcomes, with five $(50 \%)$ having bad results and five $(50 \%)$ having fair to good results. Patients in the current trial who were older did not have as excellent off a result.

\begin{tabular}{|ccccc|}
\hline $\begin{array}{c}\text { Age of the } \\
\text { Patient }\end{array}$ & $\mathbf{2 0 - 3 0}$ years & $\mathbf{3 1 - 4 5}$ years & $\mathbf{4 6 - 6 0}$ years & $\mathbf{6 1 - 7 5}$ years \\
\hline \% Of incidence & $29 \%$ & $14 \%$ & $9 \%$ & $48 \%$ \\
\hline \multicolumn{4}{c|}{ Table 1. Age Incidence } \\
\hline
\end{tabular}




\begin{tabular}{|ccccccccc|}
\hline \multirow{2}{*}{ Percentage } & Type II & \multicolumn{3}{c|}{ Type III } & \multirow{2}{*}{ Type IV } & Type V \\
and & $\mathbf{A}$ & $\mathbf{B}$ & $\mathbf{C}$ & $\mathbf{A}$ & $\mathbf{B}$ & & \\
Numbers & $19.7 \%$ & $16.2 \%$ & $0 \%$ & $45.2 \%$ & $0.6 \%$ & $8.2 \%$ & $2.1 \%$ \\
& 20 & 16 & 0 & 45 & 0 & 8 & 2 \\
\hline Table 2. Incidence Based on Seinsheimer's Classification \\
\hline
\end{tabular}

\section{DISCUSSION}

Long-bone injuries are a major socioeconomic problem. Subtrochanteric fractures have unique mechanical and anatomical characteristics that pose problems in treating long bone fractures. Closed intramedullary nails have a mechanical advantage over open intramedullary nails that solves these issues specifically. Furthermore, the advantages of low surgical exposure, efficient weight transfer through the calcar femoral, because of its short lever arm and low tensile force on the implant, the proximal femoral nail is an excellent choice for subtrochanteric fractures. The proximal femoral nail has been shown in several studies to be a successful minimally invasive implant for treating subtrochanteric fractures.

To comprehend subtrochanteric femur fracture patterns and assist therapy, a variety of classification systems have been established. The Russell-Taylor classification ${ }^{10}$ system emphasizes two different aspects of the proximal segment: Fracture involving the lower trochanter and spreading into the Piriformis fossa. The move away from intramedullary fixation using trochanteric entry nails in the treatment of subtrochanteric fractures, this classification system's value is primarily historical, still, it may influence the nail's locking configuration. Orthopaedic Trauma Association (OTA) ${ }^{7}$ system broadly classifies subtrochanteric femur fractures based on oblique, transverse, or multifragmentary inspected for associated fractures, especially those involving the femoral neck.

Young patients with comminuted subtrochanteric fractures as a result of high-energy trauma should be treated differently, according to Watson ${ }^{11}$ et al. When Fielding and Magiliato $^{12}$ reported on 64 people with subtrochanteric fractures, Boldin ${ }^{13}$ et al. reported on 73 years old. Only two patients were older than 40 , with an average age of 27.4 years. The average age of the patients was 37.5 years, with a little female preponderance of 54 percent, as reported by Akilan ${ }^{14} \mathrm{C}$, as well as Boldin et al.13 (70 percent) and Schipper ${ }^{15}$ (82 percent). K.G. Kandasamy and Shankar ${ }^{16}$ et al. reported that males were slightly more than females and the male: female ratio of 1.23: 1 . Akilan ${ }^{14} \mathrm{C}$ reported a slight male preponderance than females in his study at around $58.33 \%$. $54 \%$ involved the left femur of the Schipper series. ${ }^{15}$ The right femur was involved in 46 percent of the subtrochanteric fractures in this present series. Kandasamy ${ }^{8}$ et al. On the left and right sides of the body, injuries were found to be virtually distributed equally. The right-sided femur was impacted in 13 cases and the left-sided femur was afflicted in 12 cases in the Akilan ${ }^{14}$ study.

The majority of the patients in this study sustained fractures as a result of simple falls, and the majority of them were older women. High-velocity injuries, such as car accidents and falls from great heights, accounted for 48 percent of these fractures, with males accounting for the majority of them. According to the Kandasamy and Shankar ${ }^{8}$ et al. series, 60 percent of injuries were caused by motor accidents, whereas 40 percent were caused by falls. Highvelocity injuries account for $19 \%$ of Akilan ${ }^{14} \mathrm{C}$ studies, while low-velocity injuries account for 6\%. In W.M. Gadegone's series, ${ }^{16}$ fractures due to domestic falls account for $75 \%$, in their study in which the patient's mean age group is high. 25 percent of subtrochanteric fractures are caused by motor vehicle collisions. In this study, the interval between hospitalization and surgery varied between 3 and 26 days. In the present series, the mean interval was high and was 6.6 days, which is greater than Schipper's series ${ }^{15}$ where it was two days. According to Shankar et al. mean interval was 5.4 days. Inn Fielding and Magiliato ${ }^{12}$ et al.' study mean interval was 15.22 days. In his study, Seinsheimer ${ }^{17}$ found that type III-A fracture patterns were more common (38.29 percent) than other fracture types. The incidence of Seinsheimer's ${ }^{17}$ categorization was 41.6 percent, according to Mooney ${ }^{18}$ et al. studies.

In this series, the duration of stay was 19.09 days, while Schipper's series ${ }^{15}$ was 19 days. 92 percent by closed reduction and $8 \%$ by open reduction were achieved in his study. In ninety-five (95\%) of patients closed reduction intraoperatively was achieved, and for five patients, the delayed injury necessitated an open reduction due to the procedure time interval. Velasco and Comfort ${ }^{19}$ in their studies showed $90 \%$ by closed means and $10 \%$ by open reduction. According to Watson et al.11 if closed reduction is not possible, the comminuted pieces may become embedded in the thigh muscles, resulting in delayed or non-union.

The reduction was good in 76.01 percent of the patients, acceptable in 4.76 percent of the patients, and insufficient in nineteen (19.33\%) of patients who had unsatisfactory outcomes. In Schipper's series, 15 the decrease was good to acceptable in 96.2 percent of instances, and poor reduction was recorded in only 2.9 percent of cases. According to Kandasamy and Shankar, ${ }^{8}$ et al. the acceptable reduction was $96 \%$, good $2 \%$, poor reduction $2 \%$. In the study of Akilan, ${ }^{14}$ he noted adequate reduction was $72 \%$, good $20 \%$, the poor reduction was $8 \%$.

In the current study, seven patients (7.76\%) had a superficial infection after surgery, which was successfully treated with parenteral antibiotics. In contrast, I.B. Schipper ${ }^{15}$ observed 4.1 percent superficial and 2.5 percent deep infections after surgery. We didn't come across any deep infections in this series. Cut out of the screw was reported in five cases $(5.76 \%)$ after a fall in the postoperative period, whereas in Schipper's ${ }^{15}$ series, $6 \%$ of the patients had this problem. Three patients had a femur shaft fracture with nail breakage described at an unlocked distal locking screw hole, although I.B. Schipper ${ }^{15}$ documented this condition in $2 \%$ of his cases. In Daniel ${ }^{20}$ etal series, superficial infection noted was $2.3 \%$, no deep infection, cut out of hip screw was $1 \%$, breakage of the nail was $1.3 \%$ in Schimmermacher ${ }^{21}$ et al. studies, superficial infection noted was 3.2\%,1 \% deep infection, $0.6 \%$ cut out of the screw, $1 \%$ breakage. There were two incidences of infection in Daniel ${ }^{20}$ et al. series of eighteen subtrochanteric fractures treated with an open reduction, and one patient appeared to have persistent osteomyelitis. Open fractures occurred in five of the fifteen patients in this study, resulting in acute or chronic osteomyelitis.

The average time for the radiological union in this series was 3.02 months, whereas it took nearly four months in the I.B. Schipper ${ }^{15}$ series. Velasco and Comfort ${ }^{19}$ in their studies 
reported union for his patients for an average of 23.5 weeks Aronoff 22 et al. patients required six and a half months for the union after open reduction and internal fixation with an intramedullary rod. According to Boyd, ${ }^{23}$ the non-union rate was higher in open reduction and internal fixation patients, as well as in younger patients, Watson ${ }^{11}$ et al. found a ten percent non-union rate in young conservatively treated patients. Seinsheimer, ${ }^{17}$ Velasco and Comfort ${ }^{19}$ all reported union in their patients who were treated conservatively. Hansen and Tullos ${ }^{24}$ reported a non-union rate of $12.5 \%$ by open reduction, to $26 \%$ as reported by Fielding and Magiliato. ${ }^{12}$ The radiological union was six months, according to Schimmermacher. ${ }^{21}$

\section{CONCLUSIONS}

Patients in the older age groups did not have a good outcome in this series. These findings suggest that to reduce problems, a meticulous surgical technique and adjustments tailored to the individual fracture pattern are required. The advantages of the high rotational stability and unreamed insertion method of the head-neck fragment, as well as the potential of static or dynamic distal locking, are emphasized in osteosynthesis of the proximal femoral nail.

According to this case series, proximal femur nailing 6 is a good and appropriate implant method for patients with subtrochanteric fractures. It's nearly like a closed method, with stronger stability and early mobilization. ${ }^{6}$

Data sharing statement provided by the authors is available with the full text of this article at jemds.com.

Financial or other competing interests: None.

Disclosure forms provided by the authors are available with the full text of this article at jemds.com.

\section{REFERENCES}

[1] Tiwari M, Khan G, Rahim A, et al. A prospective study of the functional and radiological outcome of subtrochanteric femur fractures treated with proximal femur nailing. Int J Orthop Sci 2016;2(4):278-84.

[2] Pahr DH, Reisinger AG. A Review on Recent Advances in the Constitutive Modeling of Bone Tissue. Curr Osteoporos Rep 2020;18(6):696-704.

[3] Kulkarni SS, Moran CG. Results of dynamic condylar screw for subtrochanteric fractures. Injury 2003;34(2)117-22.

[4] Rog D, Grigsby P, Hill Z, et al. A biomechanical comparison of the two- and four-hole side-plate dynamic hip screw in an osteoporotic composite femur model. J Orthop Surg (Hong Kong) 2017;25(2):1-6.

[5] Kempf I, Taglang G. The gamma nail - historical background. Osteosynthesis and Trauma Care 2005;13(1):2-6.

[6] Aithala PJ, Rao S. Proximal femoral nailing: technical difficulties and results in trochanteric fractures. Open Journal of Orthopaedics 2013;3(5):234-42.

[7] Muller ME, Nazarian S, Koch P, et al. A.O. Classification of fractures-long bones. Berlin: Springer-Verlag 1987.
[8] Kandasamy KG, Shankar R. Subtrochanteric fracture of femur treated with proximal femoral nails - its functional outcome. Indian J Orthop Surg 2020;6(3):20915.

[9] Harris WH. Traumatic arthritis of the hip after dislocation and acetabular fractures: treatment by mold arthroplasty. An end-result study using a new method of result evaluation. J Bone Joint Surgery AM 1969;51(4):737-55.

[10] Russel TA, Taylor JC. Femoral subtrochanteric fractures. Browner BD. Jupiter JB, Levine AM, eds. Skeletal trauma. $2^{\text {nd }}$ edn. Philadelphia, PA: WB Saunders 1992:1832-78.

[11] Watson HK, Campbell RD, Wade PA. Classification, treatment and complications of the adult subtrochanteric fracture. J Trauma 1964;4:457-80.

[12] Fielding JW, Magiliato HJ. Subtrochanteric fractures. Surg Gynecol Obstet 1966;122(3):555-60.

[13] Boldin C, Seibert FJ, Fankhauser F, et al. The proximal femoral nail (PFN)--a minimally invasive procedure for treating unstable proximal femoral fractures: a prospective study of 55 patients with a follow-up of 15 months. Acta Orthop Scand 2003;74(1):53-8.

[14] Akilan C, Balakrishnan R, Barathiselvan V, et al. Functional outcomes of subtrochanteric fractures of femur treated with long proximal femoral nail (PFN). National Journal of Clinical Orthopaedics 2018;2(4):8-17.

[15] Schipper IB, Steyerberg EW, Castelein RM, et al. Treatment of unstable trochanteric fractures. Randomised comparison of the gamma nail and the proximal femoral nail. J Bone Joint Surg $\mathrm{Br}$ 2004;86(1):86-94.

[16] Gadegone WM, Salphale YS. Proximal femoral nail - an analysis of hundred cases of Proximal femoral fractures with an average follow-up of 1 year. Int Orthop 2007;31(3):403-8.

[17] Seinsheimer F. Subtrochanteric fractures of the femur. J Bone Joint Surg Am 1978;60(3):300-6.

[18] Mooney V, Lesin BE, Ashby ME. Cast-bracing for fractures of the femur. A preliminary report of a modified device. J Bone Joint Surg Am 1977;59(7):91723.

[19] Velasco RU, Comfort TH. Analysis of treatment problems in Subtrochanteric fractures of the femur. J Trauma 1978;18(7):513-22.

[20] Menezes DFA, Gamulin A, Noesberger B. Is the proximal femoral nail a suitable implant for treatment of all trochanteric fractures? Clin Orthop Relat Res 2005;439:221-7.

[21] Simmermacher RK, Bosch AM, Van der Werken C. The AO/ASIF-proximal femoral nail (PFN): a new device for the treatment of unstable proximal femoral fractures. Injury 1999;30(5):327-32.

[22] Aronoff PM, Davis PM, Wickstrom JK. Intramedullary nail fixation as treatment of subtrochanteric fractures of the femur. J Trauma 1971;11(8):637-50.

[23] Boyd HB, Griffin LL. Classification and treatment of trochanteric fractures. Arch Surg 1949;58(6):853-66.

[24] Hanson GW, Tullos HS. Subtrochanteric fractures of the femur treated with nail-plate devices: a retrospective study. Clin Orthop Relat Res 1978;(131):191-4. 